\title{
Decision support for multimodal transportation systems at major events and disasters: a case study in the region of Brunswick (Germany)
}

\author{
S. Detzer, M. Weber, L. C. Touko Tcheumadjeu, G. Kuhns \\ \& A. Kendziorra \\ Institute of Transportation Systems, \\ German Aerospace Center, Germany
}

\begin{abstract}
Major events and disasters endanger the efficiency of road and rail transportation systems. For rescue forces, these transportation systems, as well as information on their current conditions and capacities, are necessary to ensure emergency aid and the transportation of goods and people. In the last years, the German Aerospace Center developed a decision support tool that provides consolidated information and operation recommendations regarding individual motor car traffic based on traffic simulation. In this paper, extensions with respect to multimodal transportation systems that have been recently implemented into the existing tool to extend its capability for rescue forces are presented. These extensions concern mainly the data management and the simulation. For testing and demonstrating the tool, a scenario placed at the region of Brunswick is chosen. The main objective is to provide rescue forces in major events and disasters with the extended tool to ensure a more efficient and successful coordination.
\end{abstract}

Keywords: decision support tool, traffic management, major events and disasters, traffic simulation.

\section{Introduction}

The transportation system is a critical infrastructure and essential to the economic and social quality of life of citizens. Blackouts or disruptions of 
transportation systems have serious influences on passenger transportation, freight transportation and the supply of necessary goods and services. Hence, it is important to provide an emergency traffic management system to maintain the social need "mobility" and to support ambulance logistic by appropriate traffic measures. During and after a major event, incident or disaster, the mobility and the security of persons (e.g. individual motor car traffic and public transport), as well as goods (e.g. logistic transport), must be continuously ensured. The decision makers, like authorities and service providers, need urgently decision support information to take the right decision in real time and to be able to react effectively to the situation (e.g. closing of damaged road segments or bridges). Furthermore, they need to take useful actions to resolve the problem, like the rescue or evacuation of affected persons or to reroute trains, buses and logistic fleets, or to secure dangerous goods (see Figure 1).

In order to cope with these tasks, a system for traffic management that can also handle events/disasters is needed. In Germany, public authorities are responsible to take the according action if a major event or a disaster happens. However, an institutionalised joint traffic management is often missing in such situations. The territorial and organizational differentiation between traffic management and crisis management is one obstacle. According to Steenbruggen et al. [1], information sharing and the coordination of measures are necessary to allow ad hoc and effective decisions. For this, the German Aerospace Center (DLR) [2] developed with the participation of prospective users a system for rescue operation support to overcome the mentioned obstacle and to encourage an integral traffic management in critical situation. The system improves the interaction of emergency services (police, traffic and civil protection authorities). Information of all kind and decisions are merged through a joint traffic system. This developed decision support system is set up in the context of the project VABENE++ [3] and tested in several campaigns. Before the work described in this paper was accomplished, the system considered only individual motorised traffic. Due to the fact that not only this means of transport is affected by an extraordinary occurrence, the system is expanded by two more means of transport (freight transport and public transport) to allow a multimodal consideration. In the present paper, the extension of the decision support tool for multimodal transportation systems at major events and disasters is presented.

The paper is structured as follows: In section 2, a short overview about the project VABENE++ is given. The methods used to implement a decision support tool for multimodal transportation systems at major events and disasters are presented in section 3, with a focus on data collection, scenario, simulation, visualisation and interpretation. Finally, a conclusion and an overview for further work is given in section 4 .

\section{Short overview of the project VABENE++}

The project VABENE++ (Traffic Management for Large Scale Events and Disasters) is a project of DLR which is running until 2018. The project VABENE++ develops a system which supports the emergency services during 
incidents with information and recommendations for an effective traffic management during incidents to ensure two cases, namely logistic and efficient traffic flow to sustain the mobility and accessibility. Figure 1 shows an extract of the DLR decision support system. The initial situation is a major event, which has an impact on the modes of transport. For this situation, the tool provides an overview of the current traffic situation, as well as a prognosis how the traffic situation may evolve. The system is backed by a traffic simulation to provide quick results even for a large number of scenarios in big conurbations. With this information, the authorities are able to react and act efficiently to reach their aim (e.g. ensure the security of citizens). The decision support system was successfully demonstrated in major events and test campaigns.

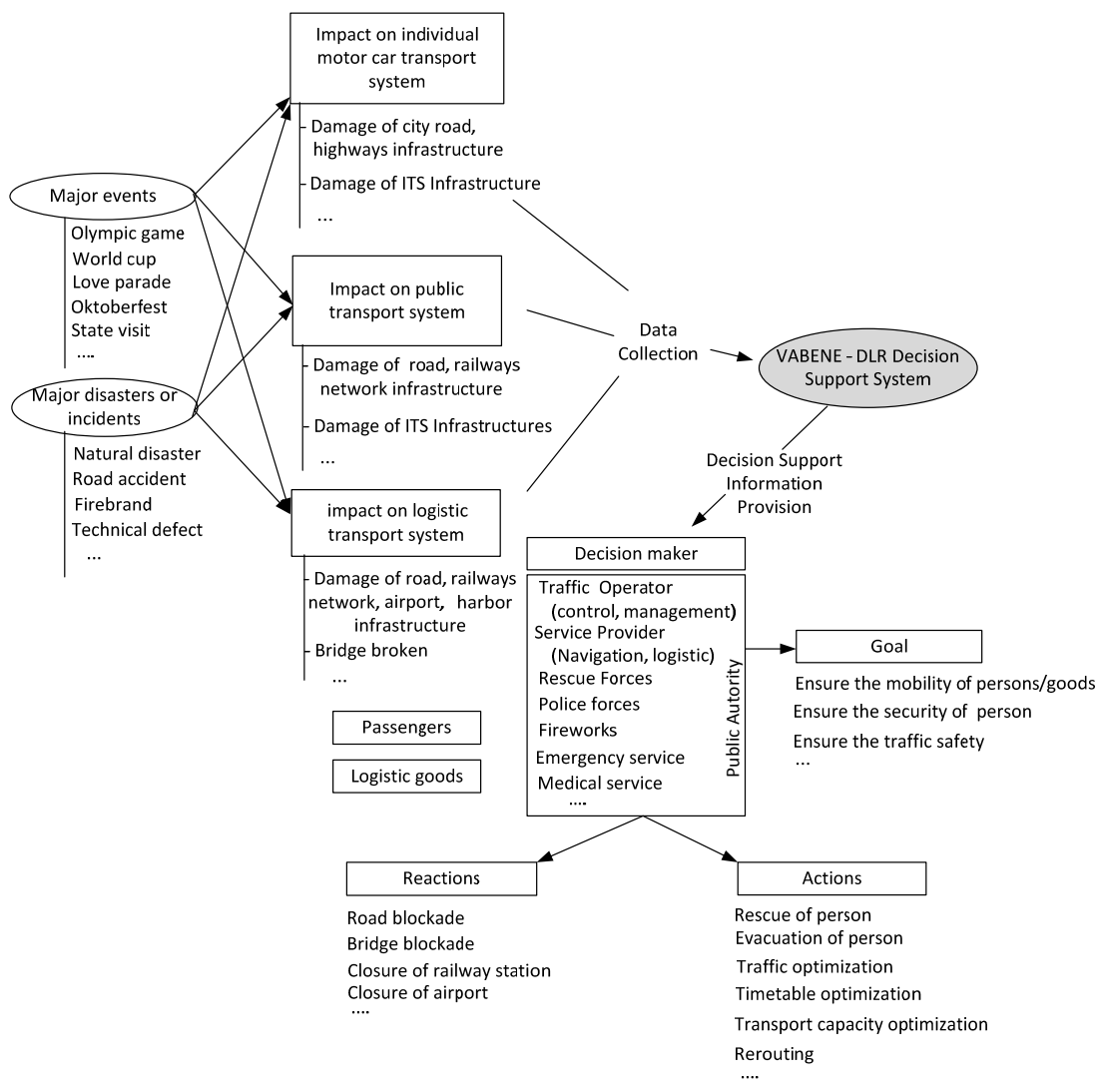

Figure 1: $\quad$ Extract of DLR decision support system.

\section{Methodology}

In the following, an overview of the methodology for the expansion of the $\mathrm{VABENE}++$ decision support tool is given. 
The DLR has many years of experience with decision support systems. In the last years, it has developed a series of decision support tools for different scenarios, to support decision makers for traffic management in case of major events or disasters, within the project VABENE++ (cp. Figure 2).

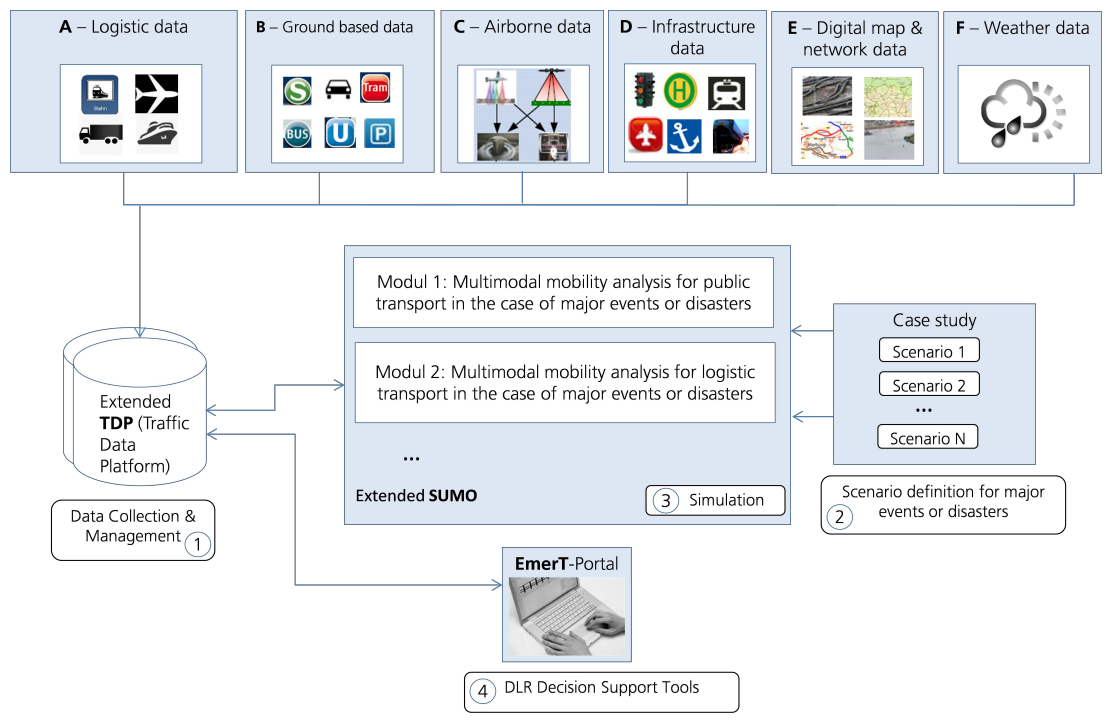

Figure 2: Overview of the system architecture of the VABENE++ decision support system.

The VABENE++ system has been recently extended with new functionalities to enable decision support information regarding for traffic and logistic fleet management at major events and disasters.

Figure 2 shows the rough system architecture of the VABENE++ decision support system, customised to support the multimodal mobility in major events and disasters that consist of four main processes:

1. Data collection and management: For the storage, management and provision of collected/processed data and generated decision support information.

2. Scenario definition for major events and disasters: Some use cases with focus on the selected topic are identified and a simulation scenario is defined.

3. Simulation: A simulation tool developed mostly by DLR that has been extended for this purpose and is used to simulate the scenarios previously defined.

4. DLR Decision Support Tool: A web based decision support tool with several functionalities to support decision makers.

All four processes will be described in detail in the following sections. 


\subsection{Data collection and management}

In the VABENE++ decision support system, data are obtained from different sources using various sensor devices like radar or a high resolution $3 \mathrm{~K}$ camera system. They are pre-processed in real time thought employing appropriate modules on the ground station as well as during the flight (by on board modules), and finally collected in the central component TDP (Traffic Data Platform) (Touko Tcheumadjeu et al. [4]). Different types of decision support information are extracted and stored in the TDP and forwarded to the VABENE++ portals which are used by rescue forces and emergency managers. The results are finally visualised, analysed, evaluated and can also be provided to traffic operators in different formats like a map using data interface compatible with the VABENE++ system.

\subsubsection{TDP (Traffic Data Platform)}

The Traffic Data Platform is the data pool of the VABENE++ decision support system and consists of databases customised for the storage and management of large amount of data. In addition the system provides also common data interfaces for users like public office and organisations with security responsibilities as well as traffic authorities to access the TDP data.

An overview about the TDP data, which can be grouped in seven categories, is shown in Table 1.

\subsubsection{Extension of the TDP to support the public and logistics transportation}

An implementation of decision-making support for multimodal public or logistic (freight) transportation requires data concerning different modes of public transport, transportation infrastructure and data concerning the freight transportation flow and fleet information for all logistic transport carriers.

All these data are needed to create a realistic model for the traffic simulation for the region selected for the scenario. The data have been requested from public and private traffic operators and been collected, consolidated and integrated into the TDP.

The logistic data consist of four parts as described below:

- Traffic infrastructure data: transport networks of different modes of transport like railways, waterways and airports

- Logistic infrastructure data: consists of freight depots, intermodal transport terminals and trans-shipment centers and airport location

- Transport operation data: statistical data including the maximum and average velocity on different routes (freight traffic and passenger traffic)

- Demand data: demand data from different modes of transport; the OriginDestination (OD) relations of different goods over all modes.

The public transport data consists of three parts as described below:

- Traffic infrastructure data: stations (including transfer options), lines and vehicles used for public transport

- Services: described by trips in connection with schedules and routes that are realised based on these schedules 
- Information: Points of interest (POI) that could be used by rescue forces in case of an emergency, like locations of their headquarters, schools, sports facilities, parking places and other infrastructure.

Table 1: Overview about the TDP supported data.

\begin{tabular}{|c|c|c|c|}
\hline No. & Data categories & Type of data & $\begin{array}{l}\text { Derived decision support } \\
\text { data/functions }\end{array}$ \\
\hline 1 & Logistic data & $\begin{array}{ll}\text { - } & \text { Floating car data (logistic fleet) } \\
\text { - } & \text { POI data } \\
\text { - } & \text { Demand data }\end{array}$ & $\begin{array}{ll} & \text { Real time traffic information } \\
\text { - } & \text { Web based fleet monitoring } \\
\text { - } & \text { Web based POIs visualisation }\end{array}$ \\
\hline 2 & $\begin{array}{l}\text { Ground based } \\
\text { data }\end{array}$ & $\begin{array}{ll} & \text { Floating car data (taxis ) } \\
\text { - } & \text { Detector data } \\
\text { - } & \text { Video data } \\
\text { - } & \text { TMC data } \\
\text { - } & \text { Traffic light information } \\
\text { - } & \text { Bluetooth data } \\
\text { - } & \text { Floating object data (FOD) } \\
\text { - } & \text { Timetable/schedule information } \\
& \text { (bus, train, tram) } \\
\text { - } & \text { Parking information }\end{array}$ & $\begin{array}{ll}\text { - } & \text { Real time traffic } \\
\text { information } \\
\text { - } & \text { Real time situation } \\
\text { information } \\
\text { - } & \text { Real time traffic monitoring } \\
\text { - } & \text { Routing based on realtime } \\
\text { conditions } \\
\text { - } & \text { Data fusion } \\
\text { - } & \text { Parking information } \\
\text { - } & \text { Traffic simulation }\end{array}$ \\
\hline 3 & Airborne data & $\begin{array}{l}\text { - Aerial image from 3/4K camera } \\
\text { system } \\
\text { - Aerial images from aerial radar } \\
\text { system }\end{array}$ & $\begin{array}{l}\text { - Real time situation assessment } \\
\text { - Real time traffic information } \\
\text { from aerial images } \\
\text { - Aerial traffic monitoring } \\
\text { - Real time Aerial image } \\
\text { visualisation } \\
\text { - Classification of open spaces } \\
\text { and assembly areas } \\
\text { - Real time state information } \\
\text { about infrastructure from the } \\
\text { aerial image }\end{array}$ \\
\hline No. & Data categories & Type of data & $\begin{array}{c}\text { Derived decision support } \\
\text { data/functions }\end{array}$ \\
\hline 4 & $\begin{array}{l}\text { Infrastructure } \\
\text { data }\end{array}$ & $\begin{array}{l}\text { - } \text { Detector positions } \\
\text { - } \text { Traffic light positions } \\
\text { - Parking positions } \\
\text { - POI data }\end{array}$ & $\begin{array}{l}\text { - Location based web } \\
\text { monitoring } \\
\text { - Web based POIs visualisation } \\
\text { - Traffic simulation }\end{array}$ \\
\hline 5 & $\begin{array}{l}\text { Digital map and } \\
\text { network data }\end{array}$ & $\begin{array}{l}\text { - Digital road, railway and } \\
\text { waterway network }\end{array}$ & $\begin{array}{l}\text { - Visualisation of digital map } \\
\text { - Traffic simulation }\end{array}$ \\
\hline 6 & Weather data & $\begin{array}{l}\text { - Precipitation, air temperature, air } \\
\text { pressure etc. }\end{array}$ & $\begin{array}{l}\text { - Risk-routing } \\
\text { - Weather information } \\
\end{array}$ \\
\hline 7 & Simulation data & $\begin{array}{l}\text { - Public transport, logistic and } \\
\text { traffic data } \\
\text { - Data from traffic demand model } \\
\text { VALIDATE } \\
\text { - } \text { Scenario data }\end{array}$ & $\begin{array}{l}\text { - Large scale traffic modelling } \\
\text { - Traffic information } \\
\text { - Traffic prediction }\end{array}$ \\
\hline
\end{tabular}

For all modes of transportation that were examined in this extension, traffic networks were created based on OpenStreetMap [5]. In addition, other data those were available in the public domain, like waterway information for ships and statistic information about logistic transport in the pilot region, have been requested from operators of traffic infrastructure. 
These networks were enriched with information on capacities as well as traffic demand under normal conditions.

The collected data on logistics and public transport is stored in a database. Since most of these data also contain or are used in connection with other spatial information, a database based on the public domain software PostgreSQL with the spatial module PostGIS is used.

\subsection{Scenario definition by major events and disasters}

One scenario was selected and has been simulated for the use case in the pilot region Brunswick, which is described in detail in the following section.

\subsubsection{Pilot region Brunswick}

For demonstrating and testing the extended disaster management system, the region of Brunswick was chosen. Brunswick is the second largest city of Lower Saxony in Germany [6]. Brunswick is the most appropriate pilot region for the case study because a large amount of relevant traffic and transport data of Brunswick is already available due to previous projects and studies. Additionally a traffic simulation of Brunswick with the software SUMO (Behrisch et al. [7]) was already set up. Another aspect is that beside individual motor car traffic public transportation and goods traffic is present in Brunswick, which is important for a multimodal consideration.

\subsubsection{Case study: multimodal mobility analysis in the case of major events and disasters}

In order to enable a multimodal consideration, a scenario-site was chosen in which individual motor car traffic, public transport and goods traffic are to such an extend impaired that an action, e.g. rerouting (see Figure 1), is required.

A railway bridge over the street "Wolfenbütteler Straße" close to the central station of Brunswick brings these three means of transport together.

There have been numerous rescue operations for various events in Brunswick in the last three years. An analysis of the rescue reports of the fire fighters in Brunswick showed that firefighting is their main task followed by technical rescues of traffic accidents [8]. Therefore, a technical disaster was selected for this scenario.

For the scenario, an incident that already occurred was chosen: A truck loaded with chemicals misjudged the height of the railway bridge and crashed. The vehicle catches fire and remains stuck below the railway bridge where it burns out completely. As a result, parts of the railway bridge are destroyed and a large area around the accident scene is blocked in a long-term due to leaking chemicals and the damaged bridge.

All traffic - road, tram and railway - is interrupted and has to be rerouted. The selected scenario arises several questions from different points of view:

a) Rescue forces: Which routes do rescue forces have to take to reach the location of the accident within the given period of time?

b) Traffic management: How far do the consequences of an incident reverberate across the transport network? How can passenger and 
freight) be rerouted efficiently? Which alternative routes exist? How is the freight transport influenced by this incident?

The scenario is simulated with unaffected traffic and with impaired traffic (disaster) with the software SUMO (e.g. Krajzewicz et al. [9]). The results of the simulation have been compared and evaluated with a view to the mentioned questions above.

\subsection{Simulation}

In the following section the traffic simulation and the results are described.

\subsubsection{SUMO}

For the implementation of the scenario, the existing traffic simulation suite "SUMO - Simulation of Urban MObility" is used. SUMO allows modelling of intermodal traffic systems including road vehicles, public transport and pedestrians. A wealth of supporting tools which handle tasks such as route finding, visualisation, network import and emission calculation is included. SUMO is mainly developed by the DLR and can be enhanced by custom models. The Brunswick scenario presented in section 3.2 has been already set up in a first version in the project "AIM - Application Platform for Intelligent Mobility" (Bauer et al. [10]) and contains data about the motorised individual traffic. The extension of this scenario done within $\mathrm{VABENE}++$ includes the railway and the public transport (buses and tram).

\subsubsection{Extension of SUMO to support the logistics, motorised individual and public transport}

To make use of the new scenario described above, SUMO was extended by new features for goods (logistic traffic) and the functionality of the public transport was improved. The enhancements include:

Table 2: $\quad$ Extension of SUMO.

\begin{tabular}{|l|l|}
\hline $\begin{array}{l}\text { Train/rail } \\
\text { way }\end{array}$ & $\begin{array}{l}\text { A new block distance concept for the trains was introduced. Trains only } \\
\text { enter the next section of track if it is not used by another train. In this } \\
\text { context, new signals have been implemented. }\end{array}$ \\
\hline $\begin{array}{l}\text { Public } \\
\text { transport }\end{array}$ & $\begin{array}{l}\text { For the public transport, transfer times at (bus-) stops have been added, } \\
\text { such that waiting times (boarding) can be displayed. }\end{array}$ \\
\hline $\begin{array}{l}\text { Logistic/ } \\
\text { goods }\end{array}$ & $\begin{array}{l}\text { A logistic concept was implemented. Individual items (goods) can be } \\
\text { transported and loaded by the vehicles of the simulation. It is possible to } \\
\text { represent whole supply chains and to follow appropriate procedures and } \\
\text { evaluate them. }\end{array}$ \\
\hline
\end{tabular}

\subsubsection{Extract from the evaluation of the Brunswick scenario}

The scenario presented in section 3.2.2 affects only a small part of the city of Brunswick, therefore only the area around the accident was considered. Figure 3 displays a comparison between the unaffected traffic (left) and impaired traffic (right) on an average day between 8 to10 o'clock in the morning rush hour. The demand is the same in both scenarios. In the case of the accident scenario, 
the road bound vehicles whose route includes the accident reroute and, therefore, avoid the accident road. The rail-bound vehicles cannot reroute, thus, they stop in front of the accident and wait. As expected, the number of vehicles increased on the alternative routes and, overall, the average travel time in this scenario is increased by $12 \%$.

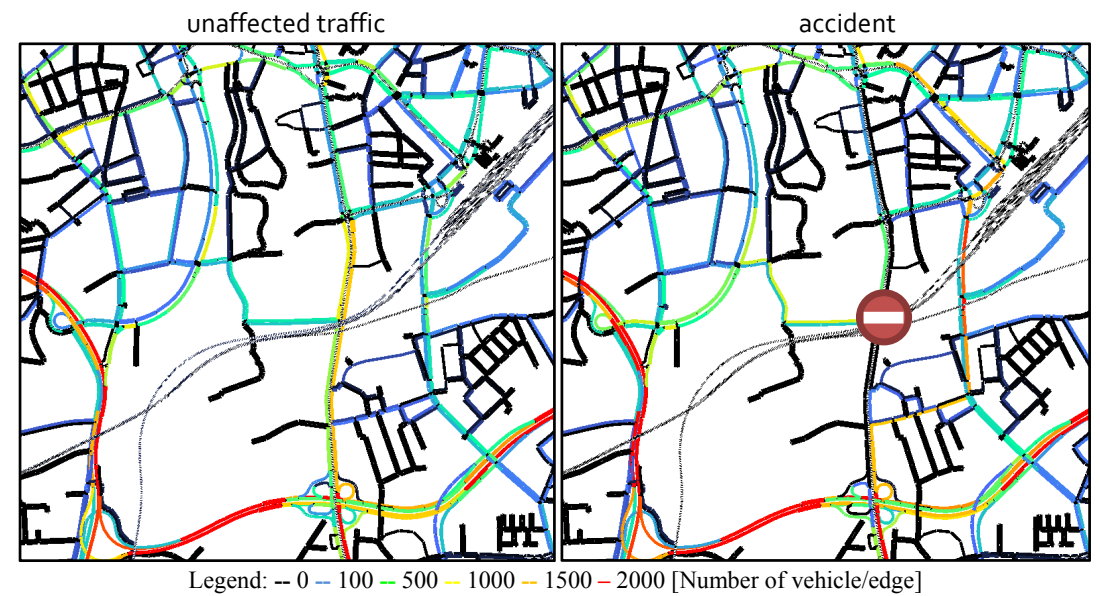

Figure 3: $\quad$ SUMO simulation - results.

In addition to this scenario, further scenarios are planned, e.g., the integration of rail replacement transport, passenger flow and the logistic transport extension.

\subsection{EmerT - the VABENE++ web based traffic decision support solution}

This section gives a short introduction about the EmerT-portal (Emergency mobility of rescue forces and regular Traffic portal) - one of the three demonstrator portals developed by DLR within the project VABENE++ as a solution to support decision making for traffic management and emergency forces. The focus lies on its extension to support the public and freight transport.

\subsubsection{EmerT-portal}

EmerT is a web-based decision support solution for displaying the current traffic situation, prediction and simulation during exceptional situations like major events, disasters, incidents or emergencies [11]. EmerT includes a range of functions and provides reliable information to facilitate decision making related to traffic management and protective measures. With its protected web interface, EmerT provides also an easy access to the data from VABENE++ system (aerial $3 / 4 \mathrm{~K}$ optical camera system, aerial radar system, micro aerial vehicles) as well as information from external systems (ground-based sensors like induction loop, floating car data, overhead sensor). 


\subsubsection{Planned extension of EmerT-portal to support logistics and public transportation}

Currently, the EmerT-portal is in a change process. The EmerT-portal will be enhanced towards a data portal that enables interoperability with existing control and command centre systems. The data exchange will follow widely accepted standards and conventions, e.g. Open Geospatial Consortium (OGC), Tile Map Service (TMS) or Open Source Geospatial Foundation (OSGeo). It is planned to extend the portal to visualise information about logistic and public transportation. The main extensions are the following ones:

Extension concerning the freight transportation:

Additional layers have to be added (see Figure 4) for the separate visualisation of transportation infrastructure, logistic infrastructures, points of interest and transfer points between different modes of transport for the region of Brunswick. General statistical information, like the average capacity of freight traffic for each mode or combined for all modes of transport and apportioned for different goods transported, can also be visualised.

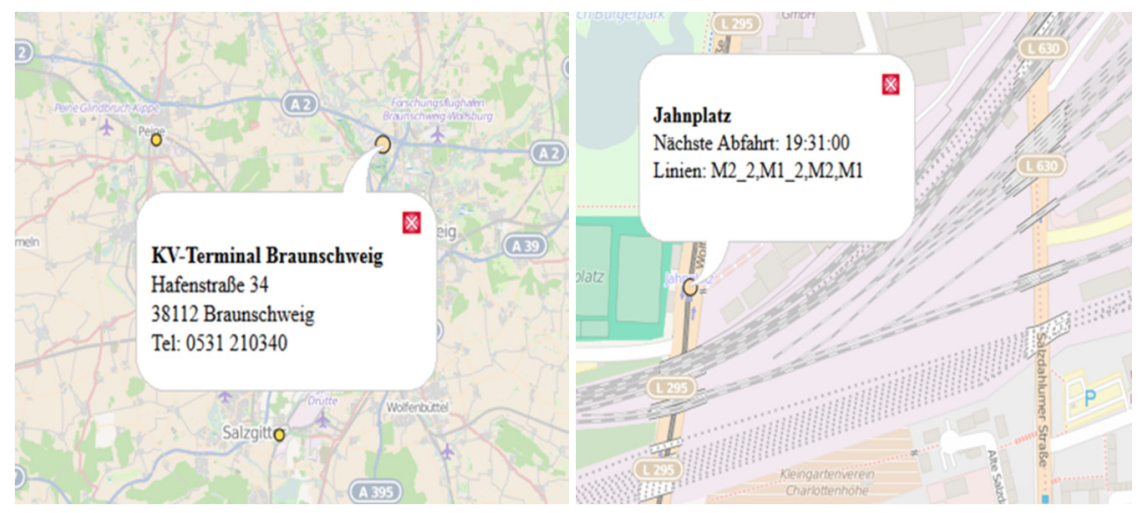

Figure 4: Visualization of some logistic transport (left) and public transport (right) features.

Extension concerning the public transportation:

Additional layers will be added (see Figure 4) for the separate visualisation of public transportation infrastructure. This includes train or tram networks as maps, points of interest (e.g. stations), routes of buses, trains and trams and their directions, the current traffic state information, the average passenger traffic (separately for each mode of transport or combined for all) and the schedule time information about each mode of transport.

\section{Conclusion and suggestions for further work}

It was aimed to expand the existing decision support system of VABENE++ by new functionalities with respect to multimodal transportation to provide a more realistic decision support. Furthermore, it was intended to test and demonstrate 
the capabilities of these new functionalities in an example scenario. To achieve the desired expansion, the system was upgraded with two more means of transportation (public transportation and freight transportation) what enables a multimodal consideration. Technically, the data management of the VABENE++ system and the simulation software SUMO was extended to achieve this.

The example scenario was placed in the region of Brunswick and considers an accident at a railway bridge that affects individual motor car traffic, public transport and goods traffic. For the development of the scenario, a broad range of data with respect to the scenario region, e.g. traffic infrastructure data of Brunswick, was gathered and incorporated into the VABENE++ system.

For comparison, the scenario was examined twice, once with the mentioned accident, i.e. with impaired traffic, and once without an accident, i.e. with unimpaired traffic. In both cases, it can be seen that public transportation and freight transportation behave fairly realistically with respect to their circumstances (impaired traffic due to an accident or not). Considering the scenario with impaired traffic, one can see how the several modes of transportation are affected (overloading, completely stopped etc.) and which consequences can be expected (traffic jam, replacement service, alternative routes etc.).

It has to be mentioned, that the data with respect to freight transportation has to be considered with care. In contrast to the very comprehensive and up-to-date data with regard to public transport, the data with regard to freight transportation are partly incomplete and estimated. For example, OD relations of goods haven't been completely available. However, the simulations based on the estimated data show adequate results, and, therefore, one can expect that realistic results will be provided by the VABENE++ system in case that accurate input data will be present.

In the future, further technical details will be implemented into the system and more realistic scenarios will be developed and examined. The technical extensions cover mainly the visualisation tasks within the EmerT-portal, but also the development of interfaces and the operational applicability in terms of the technical link to existing information systems for emergency forces.

For the improvement of the scenarios, further components (e.g. rail replacement transport, more detailed logistic transport including transfer of goods) will be added and further data will be incorporated to ensure more realistic scenarios. Also, scenarios considering further incidents (e.g. a fire at the central station) will be developed.

In summary: the extended VABENE++ system is able to predict and demonstrate impaired and unimpaired traffic with respect to individual motor car traffic, public transport and goods traffic. Hence, the objective to provide a multimodal decision support system is fulfilled, and a more realistic decision support system, by the extension of public transport and freight transport, is available for rescue forces. 


\section{References}

[1] Steenbruggen, J; Nijkamp, P.; Smits, J. M.; Mohabir, G., "Traffic incident and disaster management in the netherlands: challanges and obstacles in information sharing", Networks and Communication Studies, NETCOM, vol. 26, pp. 169-200, 2012.

[2] German Aerospace Center (DLR), "German Aerospace Center", [Online]. Available: http://www.dlr.de/dlr/en/desktopdefault.aspx/tabid-10002/ [Accessed 1301 2015].

[3] German Aerospace Center, "VABENE++ Traffic Management for Large Scale Events and Disasters," 2015. [Online]. Available: http://www.dlr.de/vabene/en/desktopdefault.aspx [Accessed 0801 2015].

[4] Touko Tcheumadjeu, L. C.; Brockfeld, E.; Ruppe, S., Traffic Data Platform as ITS Infrastructure for intelligent Traffic Data Management, Proceedings CD ROM 17th ITS World Congress 2010 Busan, Korea. 17th ITS World Congress, 2010.

[5] OpenStreetMap, "OpenStreetMap", [Online]. Available: http://www.openstreetmap.de/ [Zugriff am 1509 2014].

[6] Stadt Braunschweig, "Welcome to Braunschweig", 2014. [Online]. Available: http://www.braunschweig.de/english/index.html [Accessed 08 01 2015].

[7] Michael Behrisch, Laura Bieker, Jakob Erdmann, Daniel Krajzewicz, "SUMO - Simulation of Urban MObility, An Overview", Proceedings of SIMUL 2011, The Third International Conference on Advances in System Simulation, October 2011.

[8] Stadt Braunschweig, "Aktuelle Einsatzberichte", [Online]. Available: http://www.braunschweig.de/leben/gesundheit/feuerwehr/einsatzberichte.ht $\mathrm{ml}$ [Accessed 0801 2015].

[9] Krajzewicz, D; Erdmann, J; Behrisch, M; Bieker, L., "Recent Development and Applications of SUMO - Simulation of Urban Mobility", International Journal On Advances in Systems and Measurements, pp. 128-138, 2012.

[10] Bauer, S.; Bretschneider, E.; Rataj, J.; Schumann, T., "AIM - Application Platform Intelligent Mobility", in 16th World Congress for ITS Systems and Services, Stockholm, 21-25. September 2009.

[11] German Aerospace Center, "EmerT-Portal", [Online]. Available: http://vabene.dlr.de/Emert/EmerT_Login_Basic.html. [Accessed $16 \quad 12$ 2014]. 